\title{
CREB1, a direct target of miR-122, promotes cell proliferation and invasion in bladder cancer
}

\author{
LIHUA GUO, MIN YIN and YIXUAN WANG \\ Department of Nephrology, China-Japan Union Hospital of Jilin University, Changchun, Jilin 130033, P.R. China
}

Received February 3, 2018; Accepted June 29, 2018

DOI: $10.3892 / \mathrm{ol} .2018 .9118$

\begin{abstract}
Bladder cancer (BC) is a prevalent cancer, which arises from the epithelial lining of the urinary bladder. CAMP-response element binding protein (CREB1) acts as a transcription factor, which regulates cell transcription through phosphorylation and dephosphorylation. The purpose of this study was to explore how miR-122 worked in BC on cell proliferation and invasion. RT-qPCR was applied to evaluate the mRNA levels of CREB1 and miR-122 in BC. CCK-8 and Transwell assays were employed to determine the migratory and invasive abilities. Dual luciferase reporter assay was applied to verify miR-122 targeting CREB1 in BC. CREB1 was upregulated in bladder tissues and T24, UM-UC-3 and J82 cells, while miR-122 upregulated and had negative correlation with CREB1. Moreover, knockdown of CREB1 inhibited cell proliferative and invasive capacities. In addition, CREB1 was directly targeted by miR-122 in BC and regulated its expression. We discovered that CREB1 could reverse partially the function of miR-122 on cell proliferation and invasion. CREB1 was mediated by miR-122, and regulated cell proliferation and invasiveness. The newly identified miR-122/CREB1 axis provides novel insight into the pathogenesis of $\mathrm{BC}$.
\end{abstract}

\section{Introduction}

Bladder cancer (BC), one of the most prevalent cancers, arises from the epithelial lining of the urinary bladder, and is mainly caused by smoking and mutation (1). In current years, the standard treatment of invasive BC is radical cystectomy, although the therapeutic strategies have improved (2), the 5-year survival was $62 \%$ due to high rate of metastasis and invasion $(3,4)$. Therefore, looking for the tumor markers for early diagnosis is particularly important for treatment of bladder tumors.

Correspondence to: Dr Yixuan Wang, Department of Nephrology, China-Japan Union Hospital of Jilin University, 126 Xiantai Street, Changchun, Jilin 130033, P.R. China

E-mail: wry63e@163.com

Key words: bladder cancer, CREB1, miR-122, proliferation, invasion
CAMP-response element binding protein (CREB1), a transcription factor, regulates gene transcription through phosphorylation and dephosphorylation. CREB1, as a protooncogenic transcription factor promotes expression of its target genes taking part in metabolism and DNA repair (5). Aberrant expression of CREB1 was reported to be connected with variety of cancers, including gastric, colorectal, ovarian and breast cancers (6-9). In colorectal cancer, Ye et al discovered that CREB1 was significantly upregulated and promoted cell migration and invasion (10). Similar findings were reported by Wang et al (11) knockdown of CREB1 inhibited cell proliferation and motility in prostate cells. Therefore, we strongly believe that CREB1 could play important roles in BC.

microRNAs (miRNAs) are a class of non-coding RNA sequences with 22-28 nucleotides, which could inhibit gene expression at post-transcriptional level by binding to the 3'-untranslated region (3'-UTR) of target mRNA $(12,13)$. miRNAs are reported to be involved in several biological processes in BC, including miR-1, miR-126, miR-202 and miR-149 (14-17). There are several miRNAs binding to CREB1 and regulating the expression of CREB1 in cancers, including miR-590, miR-1224, miR-205 and miR-122 (5,18-20). miR-122, a novel microRNA, was predicted to be downregulated in many cancers including BC (21). In hepatocellular carcinoma, miR-122 inhibited epithelial-mesenchymal transition through snaill and snail2 (22). Maierthaler et al discovered that miR-122 was a prognostic marker in colorectal cancer (23). Similar finding were reported by Wang et al that miR-122 inhibited tumor growth and angiogenesis by targeting VEGFC in BC (24). In addition, Rao et al discovered that miR-122 inhibited proliferation and invasion by targeting CREB1 in gastric cancer (20). Considering these functions, to the best of our knowledge, we first propose that miR-122 regulated CREB1 expression and mediated cell proliferation and invasion in BC.

\section{Patients and methods}

Patients and clinical samples. A collection of $47 \mathrm{BC}$ tissues as well as corresponding healthy tissue samples $(5 \mathrm{~cm}$ away from the tissues) were obtained from patients who underwent surgery at China-Japan Union Hospital of Jilin University from 2015 to 2017. All samples were snap-frozen in liquid nitrogen and saved in $-80^{\circ} \mathrm{C}$ after resection. None of the patients had medication or radiation therapy. This study was 
approved by the Ethics Committee of China-Japan Union Hospital of Jilin University (Changchun, China) and obtained written informed consent from all the patients.

Cell lines and cell culture. Human BC cell lines T24, UM-UC-3 and J82 and normal bladder cells SV-HUC-1 were obtained from the American Type Culture Collection (ATCC; Rockville, MD, USA). Cells were maintained in RPMI-1640 with 10\% FBS (both from Gibco; Thermo Fisher Scientific, Inc., Waltham, MA, USA) then cultured in an incubator at $37^{\circ} \mathrm{C}$ with $5 \% \mathrm{CO}_{2}$.

RNA isolation and RT-qPCR. TRIzol reagent (Invitrogen; Thermo Fisher Scientific, Inc.) was employed to isolate RNAs, which including miRNA from the cultured cells and tissues. OneStep PrimeScript ${ }^{\circledR}$ cDNA Synthesis kit (Takara Biotechnology Co., Ltd., Dalian, China) was applied to perform reverse-transcription and synthesize first cDNA chain. Fast SYBR-Green Master Mix and TaqMan microRNA assay kits were employed to perform the RT-qPCR for CREB1 and miR-122, respectively, using ABI PRISM7900 Sequence Detection System (all from Applied Biosystems; Thermo Fisher Scientific, Inc.). GAPDH and U6 were utilized as internal reference for CREB1 and miR-122, respectively. The specific stem-loop RT primers were used for reverse transcription reaction as follows: miR-122: 5'-CTCAACTGGTG TCGTGGAGTCGGCAATTCAGTTGAGCAAACACC-3'; U6: 5'-AACGCTTCACGAATTTGCGT-3'; CREB1: F: CTTT TCTCCGGAACACAGATTTC; R: GATTTGCCAAGTGGG AGGGA; GAPDH: F: 50-CACTCCTCCACCTTTGA-30, R: 50-CCACCACCCTGTTGCTG-3'. The thermocycling parameters were $95^{\circ} \mathrm{C}$ for $3 \mathrm{~min}$ and 40 cycles of $95^{\circ} \mathrm{C}$ for $15 \mathrm{sec}$ followed by $60^{\circ} \mathrm{C}$ for $30 \mathrm{sec}$. The quantification of CREB1 or miR-122 mRNA levels was through measuring $\mathrm{Cq}$ values and normalized using the $2^{-\Delta \Delta \mathrm{Cq}}$ method (25).

Protein extraction and western blotting. The cells were washed with cold PBS buffer and extracted using RIPA lysis buffer with protease inhibitor (Beyotime Institute of Biotechnology, Shanghai, China), followed by centrifugation for $20 \mathrm{~min}$ at $4^{\circ} \mathrm{C}$ with $12,000 \mathrm{xg}$. The supernatants were collected to determine the protein concentration using BCA reagent kit (Beijing Solarbio Science \& Technology Co., Ltd., Beijing, China). The protein lysates $(50 \mu \mathrm{g} / \mathrm{lane})$ were fractionated using $10 \%$ SDS-PAGE and transferred to a PVDF membrane (Bio-Rad Laboratories, Inc., Hercules, CA, USA); The membrane was blocked using 5\% non-fat dried milk for $1 \mathrm{~h}$ at room temperature. The blots were incubated with anti-CREB1 rabbit polyclonal antibody (dilution, 1:1,000; cat. no. SAB4300519; Sigma-Aldrich; Merck KGaA, Darmstadt, Germany) and antiGAPDH (dilution, 1:3,000; cat. no. G5262; Sigma-Aldrich; Merck $\mathrm{KGaA})$ at $4^{\circ} \mathrm{C}$ overnight and anti-rabbit antibody (1:3,000; Santa Cruz Biotechnology, Inc., Dallas, TX, USA) for $2 \mathrm{~h}$ at room temperature, which was normalized by GAPDH. Signal detection employed ECL detection system (Thermo Fisher Scientific, Inc., Waltham, MA, USA).

Cell proliferation assay. The cell proliferative ability was measured by Cell Counting Kit- 8 assay (CCK-8; Dojindo Molecular Technologies, Inc., Kumamoto, Japan). A total of $100 \mu 1 \mathrm{~T} 24$ or $\mathrm{J} 82$ cells $\left(2 \times 10^{3}\right.$ cells/well) were seeded in 96-well plates and cultured for $24,48,72$ or $96 \mathrm{~h}$, respectively. Then $10 \mu \mathrm{l}$ of CCK-8 solution was added in each well and incubated at $37^{\circ} \mathrm{C}$ for $1 \mathrm{~h}$. Microplate Reader (Epoch; BioTek Instruments, Inc., Winooski, VT, USA) was applied to determine the absorbance at $490 \mathrm{~nm}$.

Transwell assay. Tanswell chambers (Corning Costar, Beijing, China) with $8 \mu \mathrm{m}$ pore size membranes were employed to assess invasive ability. Transwell chamber in 24-plate well with Matrigel (Clontech Laboratories, Inc., Mountainview, CA, USA) was coated. T2 4 or J82 cells with a density of $5 \times 10^{4}$ were added in the upper chamber in $200 \mu 1$ medium without FBS. Whereas, $500 \mu \mathrm{l}$ normal medium with $15 \%$ FBS was added in the lower chamber for use as a chemoattractant. The cells were incubated for $24 \mathrm{~h}$, and the unattached cells were removed using cotton swab. The invaded cells were fixed with methanol and then stained using $1 \%$ crystal violet; and cell counting was carried out under the microscope BX51 Olympus (Shenzhen, China).

Transfection. All vectors, including miR-122 mimic, miR-122 inhibitor, pcDNA3.1-CREB1 and luciferase reporter plasmids were purchased from Shanghai GenePharma Co., Ltd. (Shanghai, China). miR-122 mimic or inhibitor were applied to overexpress or knockdown miR-122, while siRNA-CREB1 and pcDNA3.1-CREB1 were employed to knock down or overexpress CREB1. The sequences of miR-122 mimic/inhibitorandnegativecontrol(NC)were:5'-UGGAGUGUGACAAUG GUGUUUG-3'; 5'-CAAACACCAUUGUCACACUCCA-3'; and 5'-UUCUCCGAACGUGUCACGUTT-3'. Scrambled nucleotide sequences were the NC of miR-184 inhibitor and miR-184 mimic.

Before transfection, $\mathrm{T} 24$ or J82 cells were seeded in 6-well plate and cultured overnight. A total of $4 \mu \mathrm{g}$ vectors and $8 \mu \mathrm{l}$ Lipofectamine 2000 reagent (Invitrogen; Thermo Fisher Scientific, Inc.) was mixed in $1.5 \mathrm{ml}$ microcentrifuge tube and then let stand for $20 \mathrm{~min}$; then mixed and added into cells and cultured at $37^{\circ} \mathrm{C}$ for $48 \mathrm{~h}$.

Plasmid construction and luciferase reporter assay. 3'-UTR fragment of CREB1 mRNA, containing the putative miR-122 binding sequence was amplified by PCR and cloned into pmirGlo luciferase reporter vector (named pmirGlo-CREB1WT; WT). QuikChange Multi Site-Directed Mutagenesis kit (Agilent Technologies, Inc., Santa Clara, CA, USA) was used for the site-directed mutagenesis of CREB1 3'-UTR (pmirGloCREB1-MUT; MUT) with WT as template.

For luciferase reporter assays, T24 cells were seeded into 6-well plate, miRNA-122 and WT or MUT reporter plasmid were transiently co-transfected using Lipofectamine 2000 (Invitrogen; Thermo Fisher Scientific, Inc.). After transfection for $48 \mathrm{~h}$, luciferase activity was measured using a dual-luciferase assay system (Promega Corporation, Madison, WI, USA) according to the manufacturer's instruction, which was normalized by renilla-luciferase activity.

Statistical analysis. The data are presented as mean \pm standard deviation. All statistical analyses were performed with SPSS 16.0 software (SPSS, Inc., Chicago, IL, USA). 

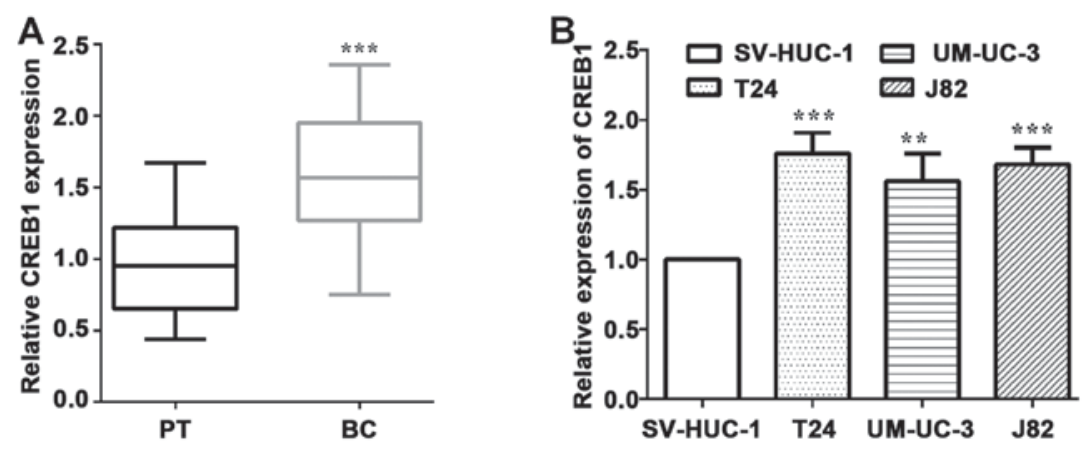

Figure 1. CREB1 is upregulated in BC tissues and cells. (A) The expression of CREB1 in BC tissues was higher than that in corresponding adjacent healthy tissues detected by RT-qPCR. (B) The levels of CREB1 were higher in BC cells T24, UM-UC-3 and J82 vs. normal cell SV-HUC-1. ${ }^{* *} \mathrm{P}<0.01$; ${ }^{* * *} \mathrm{P}<0.001$. CREB1, CAMP-response element binding protein; BC, bladder cancer.

Two-tailed Student's t-test and one-way ANOVA followed by Tukey's post hoc test were employed to analyze two groups and three or more groups, respectively. Pearson's test analysis was applied to analyze the correlations between miR-122 and CREB1 mRNA expression. $\mathrm{P}<0.05$ was considered to indicate a statistically significant difference.

\section{Results}

CREBI is upregulated in BC tissues and cells. To validate the expression of CREB1 in BC, we employed RT-qPCR to examined CREB1 expression in clinical specimens and cells lines. As shown in Fig. 1A, 49 paired of BC and corresponding healthy tissues were collected and measured the mRNA level of CREB1. As expected, CREB1 expression in $\mathrm{BC}$ tissues was significantly higher than that in the corresponding healthy tissues $(\mathrm{P}<0.0001)$ (Fig. 1A). Furthermore, CREB1 was expressed at prominently higher levels in bladder cancer patients with tumor $(\mathrm{P}=0.030)$, TNM stage $(\mathrm{P}=0.014)$, lymph node metastasis $(\mathrm{P}=0.028)$ and the expression of miR-122 ( $\mathrm{P}=0.014)$, while it had tendency to have association with invasion $(\mathrm{P}=0.053)$ (Table I). We measured the mRNA levels of CREB1 in three human BC cells and a normal bladder cell, and found that CREB1 was upregulated in $\mathrm{BC}$ T24 $(\mathrm{P}=0.0009), \mathrm{UM}-\mathrm{UC}-3(\mathrm{P}=0.0083)$ and J82 cells $(\mathrm{P}=0.0006)$, compared to the normal SV-HUC-1 cells (Fig. 1B).

Knockdown of CREBI inhibits cell proliferation and invasion. To explore the impact of CREB1, the cell proliferative and invasive abilities were measured after knockdown CREB1 in T24 cells. siRNA-CREB1 was applied to knockdown CREB1, and the CREB1 mRNA level was reduced in T24 $(\mathrm{P}=0.0010)$ and J82 ( $\mathrm{P}=0.0026)$ cells as shown in Fig. 2A and C. When CREB1 was knocked down, the absorbance was reduced in T24 and J82 cells at $72 \mathrm{~h}(\mathrm{P}=0.0053$ and 0.0080$)$ and $96 \mathrm{~h}$ ( $\mathrm{P}=0.0012$ and 0.0015$)$ (Fig. 2B and D). On the other hand, the number of invasion was reduced $(\mathrm{P}=0.0081$ and 0.0039$)$ either in T24 or J82 cells (Fig. 2E), which suggested that knockdown CREB1 inhibited cell proliferation an invasion in BC T24 and J82 cells.

miR-122 is downregulated and targeted to CREB1 in BC. As we detected the effect of CREB1 on cell proliferation
Table I. CREB1 expression and clinicopathological features in $47 \mathrm{BC}$.

\begin{tabular}{|c|c|c|c|c|}
\hline \multirow[b]{2}{*}{$\begin{array}{l}\text { Clinicopathological } \\
\text { features }\end{array}$} & \multirow[b]{2}{*}{$\begin{array}{l}\text { Cases } \\
(n=47)\end{array}$} & \multicolumn{2}{|c|}{ CREB1 expression } & \multirow[b]{2}{*}{$\mathrm{P}$-value ${ }^{\mathrm{a}}$} \\
\hline & & $\begin{array}{l}\text { Low }(\%) \\
(n=22)\end{array}$ & $\begin{array}{l}\operatorname{High}(\%) \\
(\mathrm{n}=25)\end{array}$ & \\
\hline \multicolumn{5}{|l|}{ Sex } \\
\hline Male & 27 & $13(48.1)$ & $14(51.9)$ & \multirow[t]{2}{*}{0.831} \\
\hline Female & 20 & $9(45.0)$ & $11(55.0)$ & \\
\hline \multicolumn{5}{|l|}{ Age (years) } \\
\hline$<50$ & 22 & $10(45.6)$ & $12(54.4)$ & \multirow[t]{2}{*}{0.861} \\
\hline$\geq 50$ & 25 & $12(48.0)$ & $13(52.0)$ & \\
\hline \multicolumn{5}{|l|}{ Tumor size (mm) } \\
\hline$\leq 5.0$ & 22 & $14(63.6)$ & $8(36.4)$ & \multirow[t]{2}{*}{$0.030^{\mathrm{a}}$} \\
\hline$>5.0$ & 25 & $8(32.0)$ & $17(68.0)$ & \\
\hline \multicolumn{5}{|l|}{ TNM stage } \\
\hline I-II & 21 & $14(66.7)$ & $7(33.3)$ & \multirow[t]{2}{*}{$0.014^{\mathrm{a}}$} \\
\hline III-IV & 26 & $8(30.8)$ & $18(67.2)$ & \\
\hline \multicolumn{5}{|l|}{$\begin{array}{l}\text { Lymph-node } \\
\text { metastasis }\end{array}$} \\
\hline $0-2$ & 24 & $15(62.5)$ & $9(37.5)$ & \multirow[t]{2}{*}{$0.028^{\mathrm{a}}$} \\
\hline$>2$ & 23 & $7(30.4)$ & $16(69.6)$ & \\
\hline \multicolumn{5}{|l|}{ Invasion } \\
\hline No & 25 & $15(60.0)$ & $10(40.0)$ & \multirow[t]{2}{*}{0.053} \\
\hline Yes & 22 & $7(31.8)$ & $15(68.2)$ & \\
\hline \multicolumn{5}{|l|}{ miR-122 } \\
\hline Low expression & 26 & $8(30.8)$ & $18(69.2)$ & \multirow[t]{2}{*}{$0.014^{\mathrm{a}}$} \\
\hline High expression & 21 & $14(66.7)$ & $7(33.3)$ & \\
\hline
\end{tabular}

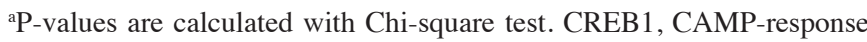
element binding protein; $\mathrm{BC}$, bladder cancer.

an invasion, we considered what impacted CREB1 and then influenced cell proliferative an invasive abilities. Therefore, we predicted microRNAs by TargetScan, and we found miR-122 was upstream of CREB1. Then, we determined miR-122 level employing RT-qPCR and found that miR-122 was downregulated $(\mathrm{P}<0.0001)$ in $\mathrm{BC}$ tissues vs. healthy tissues (Fig. 3A). Furthermore, we analyzed the expression of CREB1 and miR-122 in BC tissue samples, and discovered 

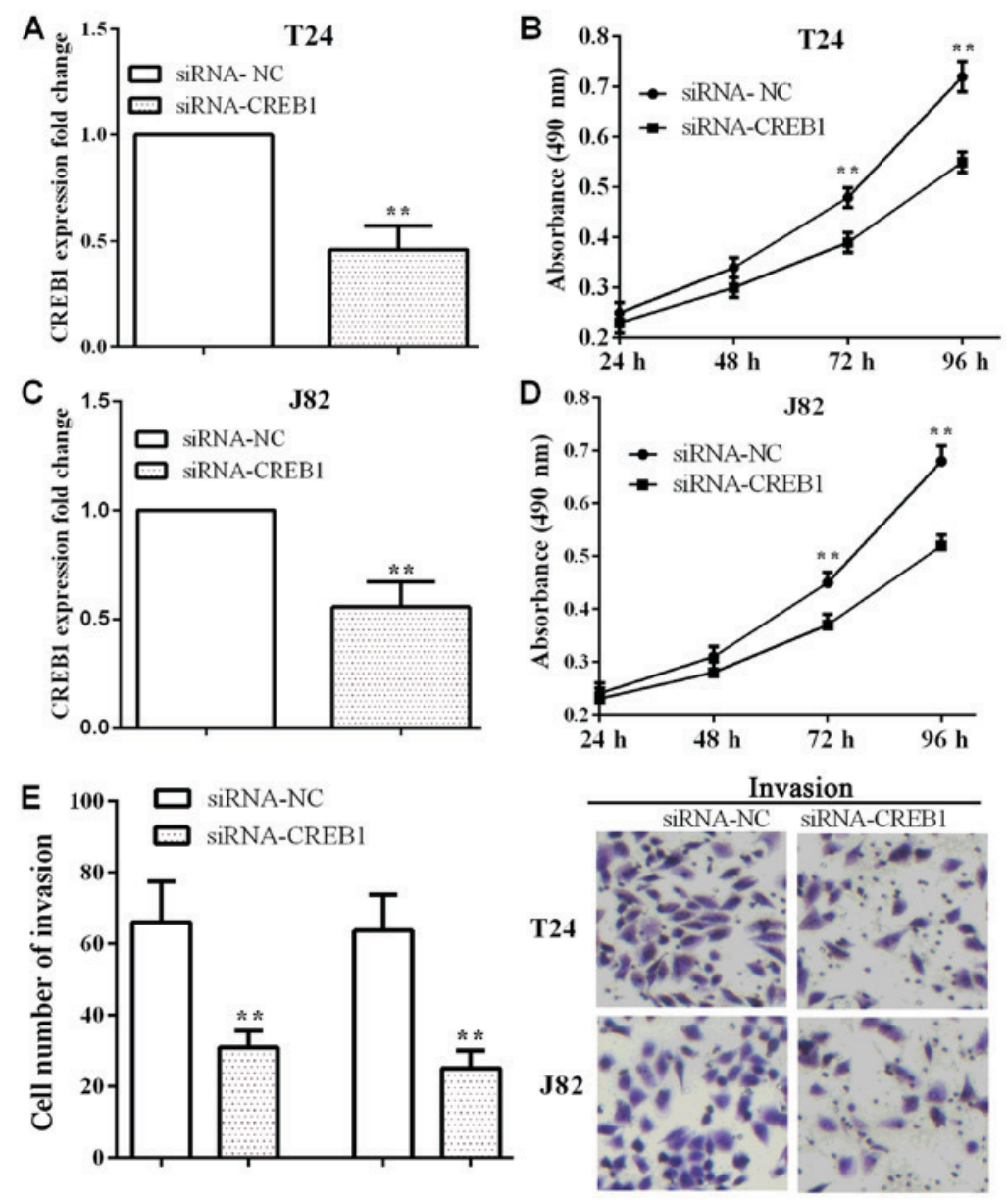

Figure 2. Knockdown CREB1 inhibits cell proliferation and invasion. (A and C) CREB1 expression was reduced in T24 and J82 cells transfected with siRNA-CREB1 compared to cells transfected with siRNA-NC detected by RT-qPCR. (B and D) Knockdown CREB1 significantly decreased the proliferative ability in T24 cells. (E) Knockdown CREB1 inhibited the invasive abilities of T24 and J82 cells (x200). ${ }^{* *} \mathrm{P}<0.01$. CREB1, CAMP-response element binding protein.

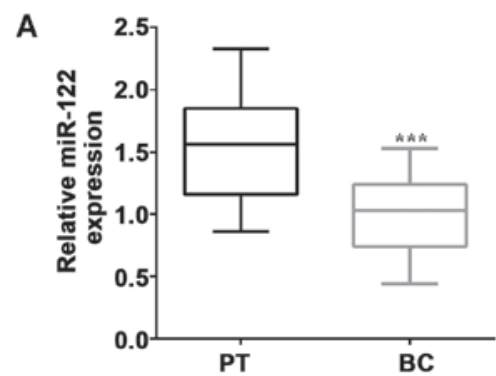

C

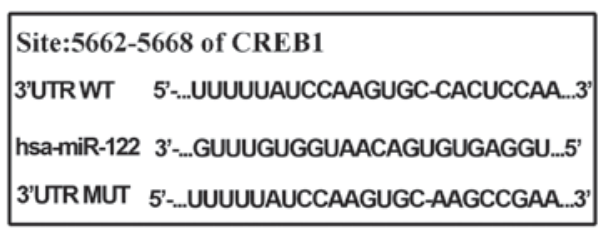

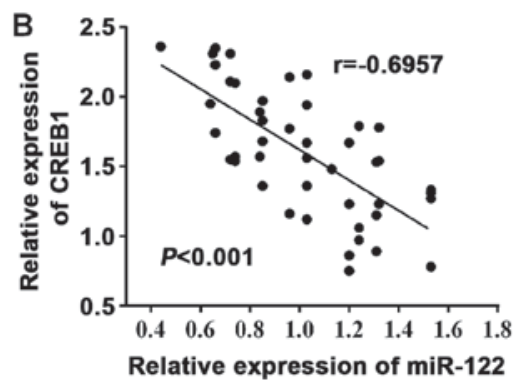

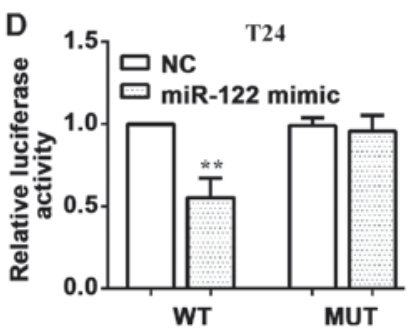

Figure 3. miR-122 is downregulated and targeted to CREB1 in BC. (A) The expression of miR-122 was determined to be downregulated in BC tissues versus healthy tissues. (B) The correlation between CREB1 and miR-122 had negative association in BC tissues explored by Pearson correlation analysis. (C) Putative seed-matching sites or mutant sites between miR-122 and 3'-UTR of CREB1. (D) Luciferase activity of A498 cells transfected with Dicer 3'-UTR luciferase reporter vector was reduced by wild-type, while the mutant 3'-UTR was not. WT, wild-type of CREB1 3'-UTR; MUT, mutant of CREB1 3'-UTR; CREB1, CAMP-response element binding protein; BC, bladder cancer. ${ }^{* *} \mathrm{P}<0.01 ;{ }^{* * *} \mathrm{P}<0.001$.

that they had a negative association between them $(\mathrm{P}<0.0001$, $r=-0.6957$ ) (Fig. 3B).
In addition, we mutated the binding sequences of miR-122 on CREB1 3'-UTR from 5'-CACUCCA-3' (WT) 
A
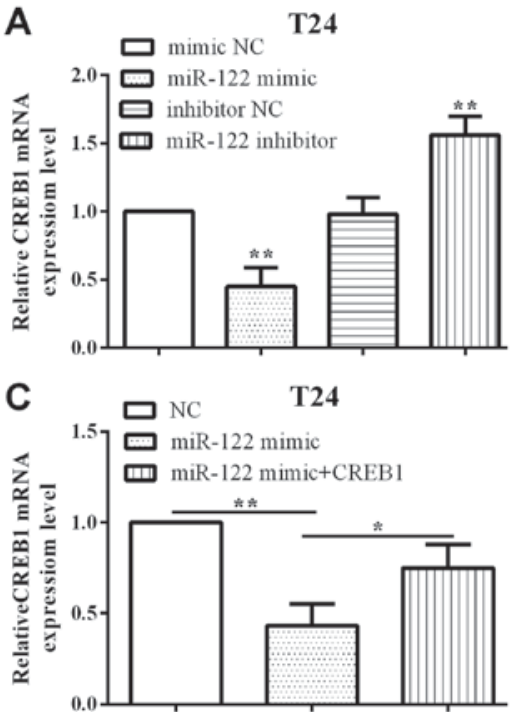

B

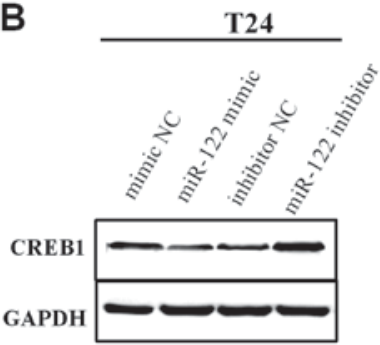

D

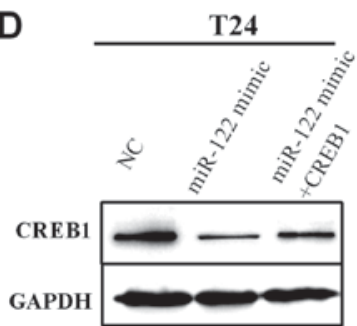

Figure 4. The changes of CREB1 mRNA and protein in altered miR-122 in T24 cells. (A and B) RT-qPCR and western blotting determined the transfection of miR-122 mimic and inhibitor on CREB1 expression. (C and D) Re-expressed CREB1 revealed the reduction by miR-122. " $\mathrm{P}<0.05$; ${ }^{* *} \mathrm{P}<0.01$. CREB1, CAMP-response element binding protein.
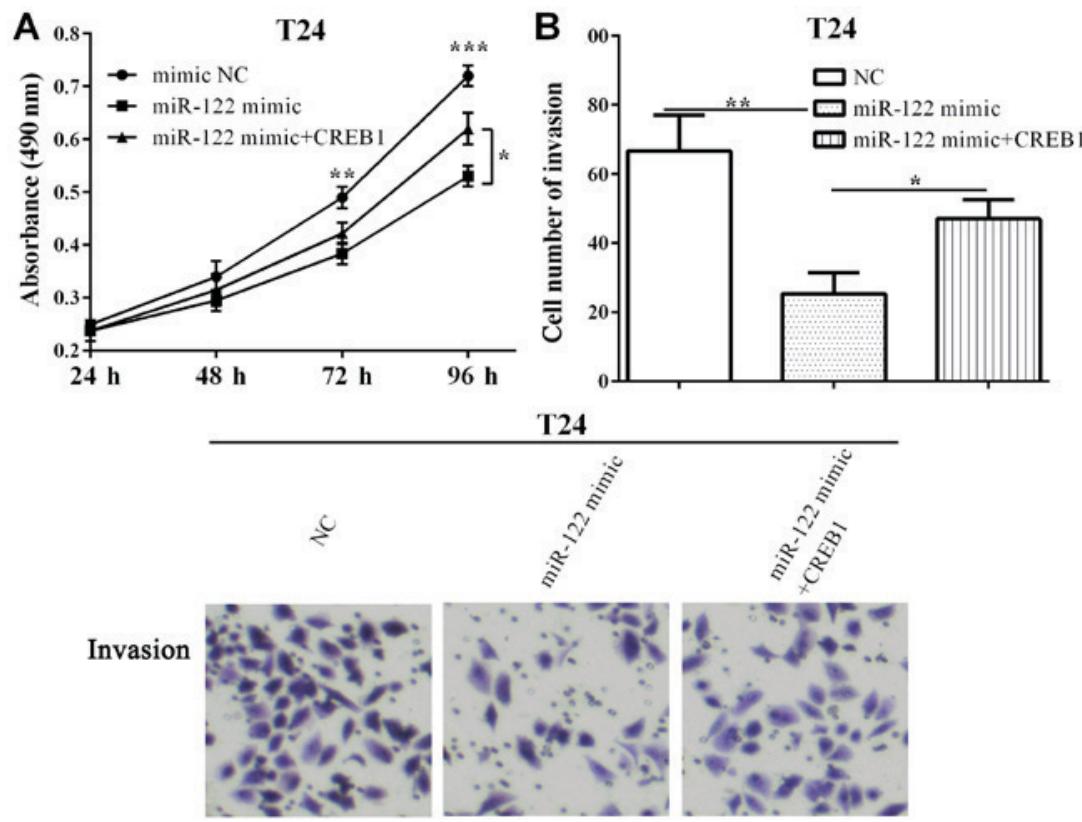

Figure 5. CREB1 mediated by miR-122 and regulation of cell proliferation and invasion in BC. (A) The proliferative ability was decreased when transfected with miR-122, which was reversed by re-expressed CREB1. (B) CREB1 could counteract the inhibitory effect of miR-122 on cell invasion in T24 cells. "P<0.05; ${ }^{* *} \mathrm{P}<0.01 ;{ }^{* * * *} \mathrm{P}<0.001$. CREB1, CAMP-response element binding protein; $\mathrm{BC}$, bladder cancer.

to 5'-AAGCCGA-3' (MUT), which were inserted into pmirGlo vector, as shown in Fig. 3C. To confirm miR-122 direct targeting to CREB1, luciferase reporter assay was performed. As expected, the luciferase activity was reduced ( $\mathrm{P}=0.0027)$ by wild-type, while the mutant was not in $\mathrm{T} 24$ cells $(\mathrm{P}=0.6194)$ (Fig. 3D).

CREB1 is mediated by miR-122 and regulates cell proliferation and invasion in $B C$. To evaluate the impact of miR-122 on CREB1, we employed miR-122 mimic and inhibitor to overexpress or knock down miR-122 and measured the CREB1 expression in T24 cells. As shown in Fig. 4A and B, when transfected with miR-122 mimic, both CREB1 miRNA and protein levels were decreased $(\mathrm{P}=0.0024)$, whereas increased $(\mathrm{P}=0.0055)$ when transfected with miR-122 inhibitor.

In addition, when overexpressed CREB1 was used pcDNA 3.1-CREB1, CREB1 expression was increased $(\mathrm{P}=0.0351)$, based on the reduction by miR-122 evaluated in T24 cells by RT-qPCR and western blotting (Fig. 4C and D).

Furthermore, the proliferative ability was decreased $(\mathrm{P}=0.0029$ and 0.0003$)$ when transfected with miR-122 after $72 \mathrm{~h}$ and $96 \mathrm{~h}$, and was reversed $(\mathrm{P}=0.0124)$ by re-expressing CREB1 at $96 \mathrm{~h}$ (Fig. 5A). Additionally, we determined the invasive ability that $\mathrm{CREB} 1$ could counteract $(\mathrm{P}=0.0105)$ and 
the inhibitory $(\mathrm{P}=0.0039)$ effect of miR-122 on cell invasion in T24 cells (Fig. 5B).

\section{Discussion}

$\mathrm{BC}$ is one of the most prevalent cancers, which arises from the epithelial lining of the urinary bladder (1). Moreover, although the therapeutic strategies have improved, the 5-year survival is $62 \%$ due to high rate of metastasis and invasion $(3,4)$. Thus, identifying new targets for the development of effective therapeutics for bladder tumors is urgent. In our study, we found that CREB1 was upregulated in bladder tissues and T24, UM-UC-3 and J82 cells, while miR-122 was upregulated and had a negative correlation with CREB1. Knockdown of CREB1 inhibited T24 and J82 cell proliferative and invasive capacities. In addition, CREB1 was directly targeted by miR-122 in BC and regulated its expression. We discovered that CREB1 could reverse the function of miR-122 partially on cell proliferation and invasion in T24 cells.

CREB1 acted as a proto-oncogenic transcription factor, promoted gene transcription through phosphorylation and dephosphorylation (5). CREB1 acted as predictor of prostate cancer recurrence and a critical driver of pro-survival, cell cycle and metabolic transcription programs (26). CREB1 was upregulated and promoted cell proliferation, invasion and acted as an independent prognostic factor in various cancers $(10,11)$. Even in BC, CREB1 was involved in EMT (27), but the underlying molecular mechanisms are still elusive. Our findings are consistent with the above findings, CREB1 was upregulated in BC tissues and cell lines. Further investigation in our present research found similar results that CREB1 promoted BC T24 and J82 cell proliferation and invasion using MTT and Transwell assays, indicating that CREB1 can be an oncogene in $\mathrm{BC}$. The data uncovered that the proliferation and invasion activity were significantly suppressed in T24 cells transfected with siRNA-CREB1 as compared with the NC group. However, the biological mechanism is unclear. The results were consistent with the findings of Shabestari et al in human pre-B acute lymphoblastic leukemia cells (28). However, due to the limitation of conditions we did not do IHC to evaluate the expression of CREB1.

miRNAs are non-coding RNAs, which inhibited gene expression at post-transcriptional level through targeting the 3'-untranslated region (3'-UTR) of target mRNA $(12,13)$. miR-122 was predicted to downregulate and inhibit cell proliferation, invasion and EMT in many cancers (22-24). In gastric cancer, CREB1 was a direct target gene of miR-122 and miR-122 regulated the expression of CREB1 (20). Consistent with previous findings of Wang et al (24), we discovered that miR-122 was downregulated in BC. Moreover, consistent with Rao et al (20), miR-122 had a negative correlation with CREB1 in BC tissues, which, to the best of our knowledge, was the first time to propose the connection between CREB1 and miR-122 in BC. We hypothesized that CREB1 may ablate the inhibitory effects of miR-122 on cell proliferation and invasion in $\mathrm{BC}$ based on these results. In order to prove this hypothesis, we examined the rescue experiments in BC T24 cells. We found that the overexpression of miR-122 inhibited cell proliferation and invasion in T2 4 cells, and CREB1 partially reversed the role of miR-122 on cell proliferation and invasion in BC. In the present study, we first proposed the relationship between CREB1 and miR-122; and we used rescue experiments to verify that miR-122 regulated cell proliferation and invasion through targeting CREB1, which was the novelty of the study.

In conclusion, we demonstrated that CREB1 acts as an oncogene in $\mathrm{BC}$ by reducing cancer growth and invasion. Moreover, we indicated that CREB1 has an inverse correlation with miR-122 and the expression of CREB1 by miR-122 in T24 cells. The newly identified CREB1 may provide further insight into the progression of $\mathrm{BC}$ and offers a promising therapeutic target for the treatment of $\mathrm{BC}$. The newly identified miR-122/CREB1 axis provides a novel insight into the pathogenesis of $\mathrm{BC}$.

\section{Acknowledgements}

Not applicable.

\section{Funding}

No funding was received.

\section{Availability of data and materials}

The datasets used and/or analyzed during the present study are available from the corresponding author on reasonable request.

\section{Authors' contributions}

LG performed the data analyses and wrote the manuscript. MY contributed significantly to analysis and manuscript preparation. YW contributed to the conception and design of the study. All authors have read and approved the final study.

\section{Ethics approval and consent to participate}

The Ethics Committee of China-Japan Union Hospital of Jilin University (Changchun, China) approved the study, and informed consent was obtained by all participants.

\section{Patient consent for publication}

Not applicable.

\section{Competing interests}

The authors declare that they have no competing interests.

\section{References}

1. Knowles MA: Molecular pathogenesis of bladder cancer. Int J Clin Oncol 13: 287-297, 2008.

2. Choueiri TK and Raghavan D: Chemotherapy for muscle-invasive bladder cancer treated with definitive radiotherapy: Persisting uncertainties. Nat Clin Pract Oncol 5: 444-454, 2008.

3. Stein JP, Lieskovsky G, Cote R, Groshen S, Feng AC, Boyd S, Skinner E, Bochner B, Thangathurai D, Mikhail M, et al: Radical cystectomy in the treatment of invasive bladder cancer: Long-term results in 1,054 patients. J Clin Oncol 19: 666-675, 2001.

4. Mayr R, Fritsche HM, Pycha A and Pycha A: Radical cystectomy and the implications of comorbidity. Expert Rev Anticancer Ther 14: 289-295, 2014. 
5. Tan X, Wang S, Zhu L, Wu C, Yin B, Zhao J, Yuan J, Qiang B and Peng X: cAMP response element-binding protein promotes gliomagenesis by modulating the expression of oncogenic microRNA-23a. Proc Natl Acad Sci USA 109: 15805-15810, 2012.

6. Gu L, Lu LS, Zhou DL and Liu ZC: UCA1 promotes cell proliferation and invasion of gastric cancer by targeting CREB1 sponging to miR-590-3p. Cancer Med 7: 1253-1263, 2018.

7. Liu Y, Lang T, Jin B, Chen F, Zhang Y, Beuerman RW, Zhou L and Zhang Z: Luteolin inhibits colorectal cancer cell epithelialto-mesenchymal transition by suppressing CREB1 expression revealed by comparative proteomics study. J Proteomics 161: 1-10, 2017.

8. Dimitrova N, Nagaraj AB, Razi A, Singh S, Kamalakaran S, Banerjee N, Joseph P, Mankovich A, Mittal P, DiFeo A, et al: InFlo: A novel systems biology framework identifies cAMP-CREB1 axis as a key modulator of platinum resistance in ovarian cancer. Oncogene 36: 2472-2482, 2017.

9. Zhu J, Zou Z, Nie P, Kou X, Wu B, Wang S, Song Z and He J: Downregulation of microRNA-27b-3p enhances tamoxifen resistance in breast cancer by increasing NR5A2 and CREB1 expression. Cell Death Dis 7: e2454, 2016.

10. Ye Q, Su L, Chen D, Zheng W and Liu Y: Astragaloside IV induced miR-134 expression reduces EMT and increases chemotherapeutic sensitivity by suppressing CREB1 signaling in colorectal cancer cell line SW-480. Cell Physiol Biochem 43: 1617-1626, 2017.

11. Wang S, Wang X, Li J, Meng S, Liang Z, Xu X, Zhu Y, Li S, $\mathrm{Wu} \mathrm{J}, \mathrm{Xu} \mathrm{M}$, et al: c-Met, CREB1 and EGFR are involved in miR-493-5p inhibition of EMT via AKT/GSK-3//Snail signaling in prostate cancer. Oncotarget 8: 82303-82313, 2017.

12. Bartel DP: MicroRNAs: Target recognition and regulatory functions. Cell 136: 215-233, 2009.

13. Ying SY, Chang DC and Lin SL: The microRNA (miRNA): Overview of the RNA genes that modulate gene function. Mol Biotechnol 38: 257-268, 2008

14. Gao L, Yan P, Guo FF, Liu HJ and Zhao ZF: MiR-1-3p inhibits cell proliferation and invasion by regulating BDNF-TrkB signaling pathway in bladder cancer. Neoplasma 65: 89-96, 2018

15. Zhai $X$ and $X u$ W: Long noncoding RNA ATB promotes proliferation, migration and invasion in bladder cancer by suppressing microRNA-126. Oncol Res: 2018 (Epub ahead of print). https://doi.org/10.3727/096504018X15152072098476.

16. Zhang L, Xu J, Yang G, Li H and Guo X: miR-202 inhibits cell proliferation, migration, and invasion by targeting EGFR in human bladder cancer. Oncol Res: 2018 (Epub ahead of print). https://doi.org/10.3727/096504018X15149787144385.

17. Yang D, Du G, Xu A, Xi X and Li D: Expression of miR-149-3p inhibits proliferation, migration, and invasion of bladder cancer by targeting S100A4. Am J Cancer Res 7: 2209-2219, 2017.
18. Qian J, Li R, Wang YY, Shi Y, Luan WK, Tao T, Zhang JX, Xu YC and You YP: MiR-1224-5p acts as a tumor suppressor by targeting CREB1 in malignant gliomas. Mol Cell Biochem 403: 33-41, 2015.

19. Zhang J, Ma Y, Wang S, Chen F and Gu Y: C/EBP $\alpha$ inhibits proliferation of breast cancer cells via a novel pathway of miR-134/CREB. Int J Clin Exp Pathol 8: 14472-14478, 2015.

20. Rao M, Zhu Y, Zhou Y, Cong X and Feng L: MicroRNA-122 inhibits proliferation and invasion in gastric cancer by targeting CREB1. Am J Cancer Res 7: 323-333, 2017.

21. Pop-Bica C, Gulei D, Cojocneanu-Petric R, Braicu C, Petrut B and Berindan-Neagoe I: Understanding the role of non-coding RNAs in bladder cancer: From dark matter to valuable therapeutic targets. Int J Mol Sci 18: E1514, 2017.

22. Jin Y, Wang J, Han J, Luo D and Sun Z: MiR-122 inhibits epithelial-mesenchymal transition in hepatocellular carcinoma by targeting Snail1 and Snail2 and suppressing WNT/ $\beta$-cadherin signaling pathway. Exp Cell Res 360: 210-217, 2017.

23. Maierthaler M, Benner A, Hoffmeister M, Surowy H, Jansen L, Knebel P, Chang-Claude J, Brenner $\mathrm{H}$ and Burwinkel B: Plasma miR-122 and miR-200 family are prognostic markers in colorectal cancer. Int J Cancer 140: 176-187, 2017.

24. Wang Y, Xing QF, Liu XQ, Guo ZJ, Li CY and Sun G: miR-122 targets VEGFC in bladder cancer to inhibit tumor growth and angiogenesis. Am J Transl Res 8: 3056-3066, 2016.

25. Livak KJ and Schmittgen TD: Analysis of relative gene expression data using real-time quantitative PCR and the 2(-Delta Delta C(T)) method. Methods 25: 402-408, 2001.

26. Sunkel B, Wu D, Chen Z, Wang CM, Liu X, Ye Z, Horning AM, Liu J, Mahalingam D, Lopez-Nicora $\mathrm{H}$, et al: Integrative analysis identifies targetable CREB1/FoxA1 transcriptional co-regulation as a predictor of prostate cancer recurrence. Nucleic Acids Res 44: 4105-4122, 2016.

27. Xu X, Zhu Y, Liang Z, Li S, Xu X, Wang X, Wu J, Hu Z, Meng S, Liu B, et al: c-Met and CREB1 are involved in miR-433-mediated inhibition of the epithelial-mesenchymal transition in bladder cancer by regulating Akt/GSK-3/Snail signaling. Cell Death Dis 7: e2088, 2016.

28. Shabestari RM, Safa M, Alikarami F, Banan M and Kazemi A: CREB knockdown inhibits growth and induces apoptosis in human pre-B acute lymphoblastic leukemia cells through inhibition of prosurvival signals. Biomed Pharmacother 87: 274-279, 2017. 